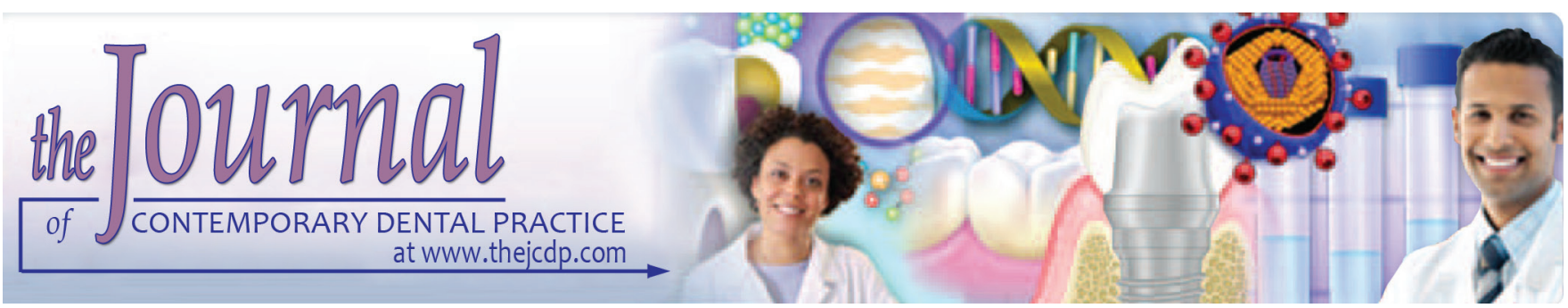

\title{
Effect of Surface Treatments on the Bond Strength to Turkom-Cera All-ceramic Material
}

\author{
${ }^{1}$ Abdul AA Razak, ${ }^{2}$ Mohamed I Abu-Hassan, ${ }^{3}$ Bandar MA AL-Makramani \\ ${ }^{4}$ Fuad A AL-Sanabani, ${ }^{5}$ Ibrahim Z AL-Shami, ${ }^{6}$ Hosain M Almansour
}

\section{ABSTRACT}

Aim: The aim of this study was to evaluate the effect of surface treatments on shear bond strength (SBS) of TurkomCera (Turkom-Ceramic (M) Sdn. Bhd., Puchong, Malaysia) all-ceramic material cemented with resin cement Panavia- $F$ (Kuraray Medical Inc., Okayama, Japan).

Materials and methods: Forty Turkom-Cera ceramic disks $(10 \mathrm{~mm} \times 3 \mathrm{~mm}$ ) were prepared and randomly divided into four groups. The disks were wet ground to 1000-grit and subjected to four surface treatments: (1) No treatment (Control), (2) sandblasting, (3) silane application, and (4) sandblasting + silane. The four groups of 10 specimens each were bonded with Panavia- $F$ resin cement according to manufacturer's recommendations. The SBS was determined using the universal testing machine (Instron) at $0.5 \mathrm{~mm} / \mathrm{min}$ crosshead speed. Failure modes were recorded and a qualitative micromorphologic examination of different surface treatments was performed. The data were analyzed using the one-way analysis of variance (ANOVA) and Tukey honestly significant difference (HSD) tests.

Results: The SBS of the control, sandblasting, silane, and sandblasting + silane groups were: $10.8 \pm 1.5,16.4 \pm 3.4$, $16.2 \pm 2.5$, and $19.1 \pm 2.4 \mathrm{MPa}$ respectively. According to the Tukey HSD test, only the mean SBS of the control group was

\footnotetext{
${ }^{1}$ Department of Restorative Dentistry, Faculty of Dentistry University of Malaya, Kuala Lumpur, Malaysia

${ }^{2}$ Faculty of Dentistry, Universiti Teknologi MARA, Shah Alam Malaysia

${ }^{3,4}$ Department of Prosthetic Dental Sciences, College of Dentistry, Jazan University, Jazan, Kingdom of Saudi Arabia

${ }^{4}$ Department of Prosthetic Dentistry, Faculty of Dentistry, Sana'a University, Sana'a, Republic of Yemen

${ }^{3,5}$ Department of Conservative Dentistry, Faculty of Dentistry Sana'a University, Sana'a, Yemen

${ }^{6}$ Department of Prosthodontics, Riyadh Colleges of Dentistry and Pharmacy, Riyadh, Kingdom of Saudi Arabia

Corresponding Author: Bandar MAAI-Makramani, Department of Prosthetic Dental Sciences, College of Dentistry Jazan University, Jazan, Kingdom of Saudi Arabia, Phone: +00966568557923, e-mail: makramani@yahoo.com
}

significantly different from the other three groups. There was no significant difference between sandblasting, silane, and sandblasting + silane groups.

Conclusion: In this study, the three surface treatments used improved the bond strength of resin cement to Turkom-Cera disks.

Clinical significance: The surface treatments used in this study appeared to be suitable methods for the cementation of glass infiltrated all-ceramic restorations.

Keywords: Adhesion, Cements, Ceramics, Shear bond strength.

How to cite this article: Razak AAA, Abu-Hassan MI, AL-Makramani BMA, AL-Sanabani FA, AL-Shami IZ, Almansour HM. Effect of Surface Treatments on the Bond Strength to Turkom-Cera All-Ceramic Material. J Contemp Dent Pract 2016;17(11):920-925.

Source of support: Nil.

Conflict of interest: None.

\section{INTRODUCTION}

The patients' desire for all-ceramic restorations has increased because of their esthetic performance, biocompatibility, and improved mechanical properties. Likewise, high-strength aluminum oxide ceramics have been widely used because of their inherent chemical stability, physical, and mechanical characteristics. ${ }^{1}$

Appropriate selection and application of luting agents for permanent cementation of all-ceramic restorations are crucial factors for their clinical success. Bonding of ceramic to dental tissue depends on the adhesion of luting cement to the ceramic and enamel and/or dentin. Longterm stable ceramic-resin bonds rely on chemical bonds and micromechanical interlocking at the resin-ceramic interface. $^{2}$

In order to enhance the bond strength of luting cement to the ceramic surface, different surface treatments on 
ceramic surface have been recommended, such as sandblasting, etching with different acids, and grinding with diamond burs. ${ }^{3-6}$ All of these procedures are intended to improve the bond strength by producing micromechanical retention, and thus, modifying the porcelain surface texture. ${ }^{7}$

In addition to this mechanically retentive surface, the use of silane-coupling agent provides a chemical interaction, which is attributed to its bifunctional characteristic. A high proportion of porcelain allows reaction of the silane agent, both to the crystal portion of the treated porcelain and to the organic portion of the luting agent. ${ }^{8-10}$

Previous studies have revealed that most clinical failures would initiate from the cementation or internal surfaces. ${ }^{11-13}$ Therefore, the integrity of the luting cement to ceramic surfaces plays a significant role in the longevity of the restorations; the failures originating from cementation surfaces identified the necessity for a consistent conditioning method to strengthen this critical area.

The effect of different surface treatments on the bond strength to Turkom-Cera, a high-strength aluminum oxide ceramic material, has not been studied. Therefore, the objectives of this in vitro study are:

- To compare the effect of various surface treatments on the shear bond strength (SBS) of Turkom-Cera when luted with resin-based cement.

- To investigate the association between SBS and modes of failure.

\section{MATERIALS AND METHODS}

\section{Materials Used}

Forty Turkom-Cera (Turkom-Ceramic (M) Sdn. Bhd., Puchong, Malaysia) ceramic disks (10 $\mathrm{mm}$ in diameter and $3 \mathrm{~mm}$ thick) were prepared and used in this study. A resin luting cement Panavia-F (Kuraray Medical Inc., Okayama, Japan) was used.

\section{Methods}

\section{Preparation of the Specimen before Surface Treatment and Bonding}

Perspex split mold with five circular openings of $10 \mathrm{~mm}$ diameter and $3 \mathrm{~mm}$ thickness was used for the preparation of the Turkom-Cera disk specimens. A total of 40 Turkom-Cera ceramic disks with $10 \mathrm{~mm}$ diameter and $3 \mathrm{~mm}$ thickness were prepared according to manufacturer's instructions.

To ensure accurate SBS testing of the ceramic-cement interface, each specimen was embedded in a die stone (Densite, Shufo, Kyoto, Japan) using plastic mold $30 \mathrm{~mm}$ in diameter and $30 \mathrm{~mm}$ high. The bonding surface of the specimens was at the same level of the embedding medium to form one flat surface.
After hardening for 24 hours at room temperature, the bonding surface of the specimens were sanded with a series of silicon carbide ( $\mathrm{SiC}$ ) abrasive papers in sequence (No. 400, 600, 800 and 1000 grit, Buehler) using a water-irrigated lapping machine (Metaserv ${ }^{\circledR}$ 2000, Buehler, UK) until the ceramic disk was perfectly flushed with the mounting mold and a flat surface was attained.

All specimens were rinsed under running water and dried before further treatment. The ground bonding surface was examined under microscope (Zoom Stereo EMZ-1, MEIJI Techno Co., Ltd., Saitama, Japan) at 30x magnification to ensure that no abrasive particles were left on the surface.

\section{Surface Treatments and Sample Distribution}

The following surface treatments have been applied:

- Polishing with silicone carbide paper up to 1000 grit (control).

- Polishing with silicone carbide paper up to 1000 grit+ sandblasting.

- Polishing with silicone carbide paper up to 1000 grit+ silane.

- Polishing with silicone carbide paper up to 1000 grit+ sandblasting + silane.

According to surface treatments and the resin luting cement Panavia-F used, four different groups were evaluated.

Group 1: Control + resin cement

Group 2: Sandblasting + resin cement

Group 3: Silane + resin cement

Group 4: Sandblasting + silane + resin cement.

\section{Bonding Procedure}

The samples were mounted and secured on the shear bond test apparatus recommended by $\mathrm{ISO}^{14}$ in order to bond a uniform amount of cement onto the bonding surface of Turkom-Cera disk. The alignment apparatus consists of a holder for the specimen, a cylindrical split brass mold resulting in samples with a clear bond area of $3 \mathrm{~mm}$ diameter and $3 \mathrm{~mm}$ height, a silicone pad, and an added load of $1 \mathrm{~kg}$ (Fig. 1).

The resin cement was mixed as per manufacturer's recommendations. The paste was used within 3 minutes after mixing. The silane coupling agent used was a mixture of Clearfil SE Bond Primer and Clearfil Porcelain Bond Activator.

Sandblasting was performed with 50- $\mu$ m aluminum oxide $\left(\mathrm{Al}_{2} \mathrm{O}_{3}\right)$ particles at an air pressure of 2.5 bars for 13 seconds from a distance of $10 \mathrm{~mm}$. The disks were then steam cleaned and air dried. 


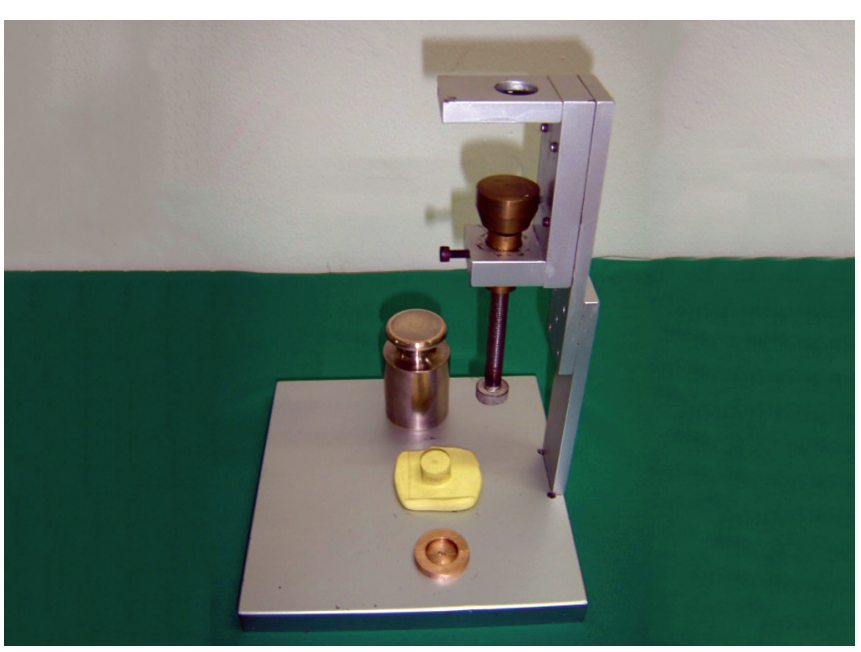

Fig. 1: The shear bond test apparatus used

The brass split mold was carefully adapted to the bonding surface by raising the mounted specimen using the screw at the bottom of the mounted specimen. The split mold together with the mounted specimen was then quickly secured onto the bonding apparatus and tightly screwed. The cements were placed, using a plastic instrument, into the $3 \mathrm{~mm}$ diameter hole in the brass split mold. A sharp blade was used to remove the excess cement before setting from the top of the brass split mold. A layer of Oxyguard II (oxygen-blocking gel) was then applied.

Specimens were allowed to set under a constant load of $1 \mathrm{~kg}$ for 15 minutes using a polyvinylsiloxane (Express putty, 3M ESPE, St Paul, MN, USA) putty mold that was placed over the brass split mold and held in place by the weight. The $1 \mathrm{~kg}$ load was removed and the samples were allowed to set at room temperature for an additional 30 minutes.

The samples were carefully removed from the apparatus and the brass split mold was separated using a sharp blade. Then, the specimens were stored in distilled water at $37^{\circ} \mathrm{C}$ for 24 hours before testing.

\section{Testing Procedure}

The bonded specimens were mounted in an $\mathrm{ISO}^{14}$ shear test jig and tested using a universal testing machine (Instron, Instron Corp., UK). The shear test jig consists of a solid block for holding the specimen and a vertical shearing blade with a $0.5-\mathrm{mm}$ blunt edge.

The 0.5-mm knife-edge shearing blade was mounted on the crosshead of the Instron testing machine and applied a shearing load to the adhesive interface at a crosshead speed of $1 \mathrm{~mm} / \mathrm{min}$. The knife-edge shearing blade was placed at a distance of approximately $0.5 \mathrm{~mm}$ above the bonded specimen at their adhesive interface (Fig. 2).

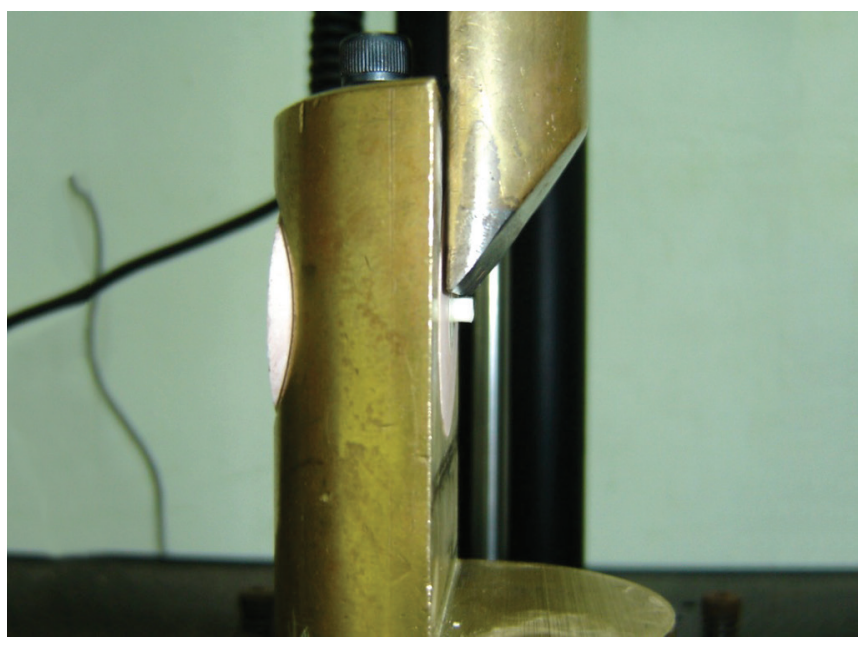

Fig. 2: Specimen during SBS testing

The maximum load at failure was recorded in Newton, and the SBS of the specimens was calculated and expressed in MPa by dividing the force $(\mathrm{N})$ at which the bond failure occurred by the bonding area $\left(\mathrm{mm}^{2}\right)$.

\section{Assessment of Mode of Failure}

The bonded surfaces were observed under a microscope (Zoom Stereo EMZ-1, MEIJI Techno Co., Ltd., Saitama, Japan) at $30 \times$ magnification to evaluate adhesive and cohesive failure modes. The failure modes were categorized as follows:

- Adhesive failure at the ceramic-cement interface.

- Cohesive failure within the cement or ceramic.

- Mixed failure: Combination of adhesive and cohesive failures.

\section{Statistical Analysis}

Descriptive statistics of SBS were performed. To compare SBS between the four groups, one-way analysis of variance (ANOVA) was conducted. A post hoc test using Tukey's honestly significant difference (HSD) test was performed to test which pair of groups differ from each other significantly.

Regarding the association between SBS and modes of failure, descriptive statistics for modes of failure and SBS was recorded and the result was descriptively analyzed. The Statistical Package for the Social Sciences (SPSS, SPSS Inc., Chicago, IL) software package was used to perform the statistical analysis. Statistical significance was set at $\alpha=0.05$.

\section{RESULTS}

The mean SBS and standard deviation for all groups are given in Graph 1.

According to one-way ANOVA, there was a significant difference in SBS between the four groups $(p<0.001)$. 


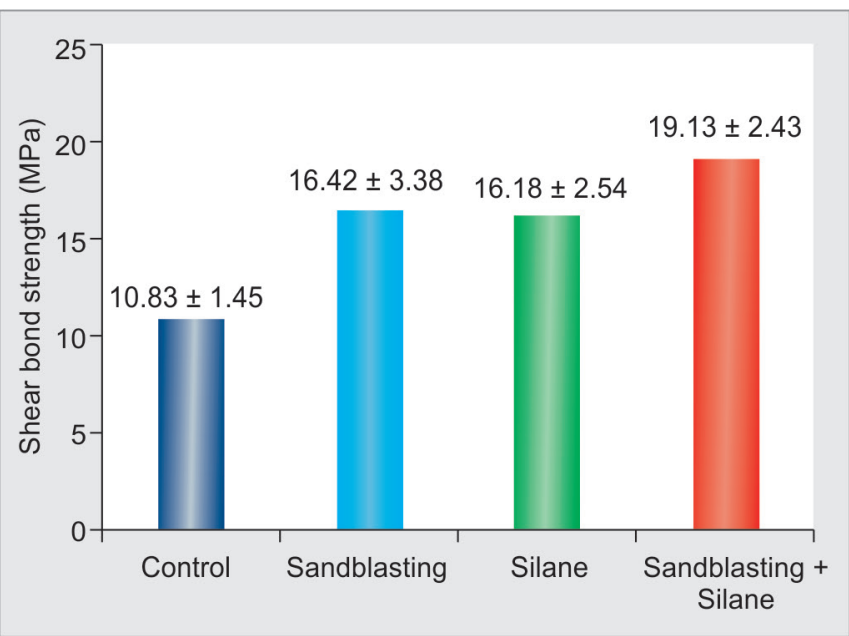

Graph 1: Mean SBS (MPa) of the four treatment groups

Table 1: Multiple pairwise comparisons of SBS (MPa) of the four surface treatments using Tukey's HSD test

\begin{tabular}{llcc}
\hline Pairwise comparison & Mean (SD) & $\begin{array}{l}\text { Mean } \\
\text { difference }\end{array}$ & $p$-value \\
\hline Control vs Sandblasting & $10.83(1.45)$ & -5.59 & $<0.001^{*}$ \\
& $16.42(3.38)$ & 5.59 & \\
Control vs Silane & $10.83(1.45)$ & -5.35 & $0.001^{*}$ \\
& $16.18(2.54)$ & 5.35 & \\
Control vs Sandblasting + & $10.83(1.45)$ & -8.29 & $<0.001^{*}$ \\
silane & $19.13(2.43)$ & 8.29 & \\
Sandblasting vs Silane & $16.42(3.38)$ & 0.24 & 0.10 \\
& $16.18(2.54)$ & -0.24 & \\
Sandblasting vs & $16.42(3.38)$ & -2.7 & 0.10 \\
Sandblasting + silane & $19.13(2.43)$ & 2.7 & \\
Silane vs Sandblasting + & $16.18(2.54)$ & -2.94 & 0.06 \\
silane & $19.13(2.43)$ & 2.94 & \\
\hline
\end{tabular}

*Two pairs of means are significantly different by Tukey's HSD test

Multiple comparisons using Tukey's HSD post hoc test was used to determine the pair of means that differ significantly (Table 1). Based on Tukey's HSD test, the control group $(10.8 \pm 1.5 \mathrm{MPa})$ showed significantly lower mean SBS than the other three groups $(\mathrm{p}<0.001)$. There was no significant difference between the mean SBS of the other three groups, sandblasting $(16.4 \pm 3.4 \mathrm{MPa})$, silane $(16.2 \pm 2.5 \mathrm{MPa})$, and sandblasting + silane $(19.1 \pm 2.4 \mathrm{MPa})(\mathrm{p}>0.05)$.

\section{TESTING MODE OF FAILURE}

A cross-tabulation between treatment groups and modes of failure was obtained. It was clear that the modes of failure were $100 \%$ adhesive in the control group. The sandblasting and silane groups showed $70 \%$ adhesive mode for each. While in the sandblasting + silane group, the modes of failure were only $50 \%$ adhesive.

Descriptive summary for modes of failure and SBS was recorded. The SBS for the mixed mode of failure (19.72-21.32 MPa) was higher compared to that of the adhesive mode (10.83-16.93 MPa).

\section{DISCUSSION}

In the present study, shear bond test was used to evaluate the effect of different surface treatments on the bond strength of resin cement to Turkom-Cera.

It has been shown that removal of the limited amount of glassy matrix present in glass-infiltrated alumina ceramic materials by etching did not result in a significant amount of microscopic retentive features..$^{15}$ Sandblasting, using aluminum oxide particles, is an alternative method for creation of micromechanical retention. This technique was utilized in the present study for being a commonly method employed to increase roughness of high-strength ceramic materials. ${ }^{3,4,15-17}$

Surface roughening methods improve surface energy and, therefore, its wettability. ${ }^{18}$ Mechanical interlocking of the cements to roughened ceramic specimens will enhance bond strength values. The present study demonstrated that roughening of the Turkom-Cera surface increased the adhesion of resin cement. The data clearly showed that sandblasting the surface with alumina particles was effective surface treatment for producing high bond strength. The bond strength values differed significantly between the control group $(10.8 \pm 15 \mathrm{MPa})$ and the sandblasted group $(16.4 \pm 3.4 \mathrm{MPa})$. These results agree with the findings of previous studies which have found a strong and durable bond between Panavia resin luting cement and air particle-abraded high-alumina. ${ }^{4,15,19,20}$

The mechanical retention provided by surface treatment is of greater importance for appropriate adhesion. However, the association with a chemical procedure (silanization) is required for better results. ${ }^{19,21-24}$ Thus, a silane coupling agent was also used in the present study for the same reason.

Silane coupling agents provide covalent chemical bonds between silica/ceramic surfaces and bonding agent/resin cements as well as a rewetting effect on the roughened ceramic surface. The exact role of rewetting effects, micromechanical interlocking, and chemical interaction of silane coupling and bonding agents on the resin bond to high-alumina ceramic surfaces is still unclear. ${ }^{3,25}$

In this study, the surface treatment by silane coupling agent improved the SBS of Panavia-F to polished ceramic surfaces. The group treated with silane coupling agent $(16.2 \pm 2.5 \mathrm{MPa})$ showed significantly greater SBS than the non-silanated group (control) $(10.8 \pm 1.5 \mathrm{MPa})$. These results do not correspond with those of previous studies which showed that resin cement performed better without silane coupling agent. ${ }^{3,4,25}$

On the other hand, these results correspond to the results of other works which found that the use of the recommended silane coupling agent with Panavia resulted in significantly higher bond strength values before and after long-term storage and thermocycling. ${ }^{23,26}$ 
In this study, the specimens were silanated with a mixture of Clearfil Porcelain Bond Activator, which contained 3-methacryloxypropyl trimethoxysilane (gamma-MPTS), and Clearfil SE Bond Primer, which contained acidic phosphate ester monomer 10-methacryloyloxydecyl dihydrogen phosphate (MDP) that promotes the catalysis of silane reaction. In addition, the phosphate ester group of the adhesive monomer MDP bonds chemically to metal oxides, such as aluminum oxides. ${ }^{4,25,27}$ The exact bonding mechanisms and the role of these monomers when bonding to oxide-based ceramics are still unknown. ${ }^{25}$ However, the high bond strength may be due to the ceramic oxide and ester bond and the mechanical properties of Panavia-F cement. ${ }^{28}$

It has been found that the presence of the glassy phase in ceramics facilitates better siloxane bonds. ${ }^{6}$ The silanol groups then further react to form a siloxane network with the silica on the surface. Turkom-Cera ceramic system tested in this study is based on glass infiltration technique. Most probably, the glass infiltration facilitated better silane bonding, and therefore, superior bond strength values were obtained for these ceramics.

In the current study, a mean SBS value up to $19.1 \pm$ 2.4 MPa was achieved with Panavia-F resin cement on the sandblasted and silanated Turkom-Cera specimens. For specimens silanated with Clearfil silane $(16.2 \pm 2.5 \mathrm{MPa})$ or sandblasted with $50-\mu \mathrm{m} \mathrm{Al}_{2} \mathrm{O}_{3}$ particles $(16.4 \pm 3.4 \mathrm{MPa})$, the result was lower, but not significantly different. This finding confirmed that Panavia-F cement in combination with silane or sandblasting is suitable for bonding TurkomCera material, and stressed the importance of the selection of appropriate surface treatments for optimal bonding.

After different surface treatments to Turkom-Cera specimens, fracture analysis regarding adhesive, cohesive, or complex failures has been done. For the control group, the resin cement Panavia-F showed completely adhesive failure for all specimens. Complex adhesive and cohesive failures were also seen in this study. When Turkom-Cera was treated with Clearfil silane or abraded with 50-um $\mathrm{Al}_{2} \mathrm{O}_{3}$ particles, Panavia-F has shown complex adhesive and cohesive failures in $30 \%$ of specimens in each group. This increased to 50\% when Panavia-F cement was used with sandblasted and silanated Turkom-Cera specimens.

Particularly interesting was the fact that all complex failures were seen in the specimens that exhibited high bond strengths of more than $18 \mathrm{MPa}$. It seems that the bond strength values may be accountable for the modes of failure at the bonded interface. ${ }^{29}$

\section{CONCLUSION}

- Within the limitations of this in vitro study, it was found that when using Panavia-F resin cement and Clearfil silane, sandblasted Turkom-Cera specimens produced the highest mean SBS values. Almost similar SBS values were obtained for Turkom-Cera specimens when sandblasted with $50-\mu \mathrm{m} \mathrm{Al}_{2} \mathrm{O}_{3}$ or silanated with Clearfil silane. Therefore, these three surface treatments appeared to be the methods of choice for the cementation of Turkom-Cera restorations.

- In this study, all complex failure modes were seen in the specimens that exhibited high bond strengths of more than $18 \mathrm{MPa}$. Therefore, it can be concluded that higher bond strength values increase complex (adhesive and cohesive) failure modes.

\section{REFERENCES}

1. Al-Makramani BM, Razak AA, Abu-Hassan MI. Effect of luting cements on the compressive strength of TurkomCera $^{\mathrm{TM}}$ all-ceramic copings. J Contemp Dent Pract 2008 Feb;19(2):33-40.

2. Blatz MB, Richter C, Sadan A, Chiche GJ. Critical appraisal. Resin bond to dental ceramics, Part II: high-strength ceramics. J Esthet Restor Dent 2004 Sep;16(5):324-328.

3. Kern M, Thompson VP. Bonding to glass infiltrated alumina ceramics: adhesive methods and their durability. J Prosthet Dent 1995 Mar;73(3):240-249.

4. Friederich R, Kern M. Resin bond strength to densely sintered alumina ceramic. Int J Prosthodont 2002 Jul-Aug;15(4):333-338.

5. Janda R, Roulet JF, Wulf M, Tiller HJ. A new adhesive technology for all-ceramics. Dent Mate 2003 Sep;19(6):567-573.

6. Valandro LF, Ozcan M, Bottino MC, Bottino MA, Scotti R, Bona $\mathrm{AD}$. Bond strength of a resin cement to high-alumina and zirconia-reinforced ceramics: the effect of surface conditioning. J Adhes Dent 2006 Jun;8(3):175-181.

7. Filho AM, Vieira LC, Araújo E, Monteiro Júnior S. Effect of different ceramic surface treatments on resin microtensile bond strength. J Prosthodont 2004 Mar;13(1):28-35.

8. Nagayassu MP, Shintome LK, Uemura ES, Araújo JE. Effect of surface treatment on the shear bond strength of a resin-based cement to porcelain. Braz Dent J 2006 Jul-Aug;17(4):290-295.

9. Kim TH, Jivraj SA, Donovan TE. Selection of luting agents: part 2. J Calif Dent Assoc 2006 Feb;34(2):161-166.

10. Matinlinna JP, Vallittu PK. Bonding of resin composites to etchable ceramic surfaces - an insight review of the chemical aspects on surface conditioning. J Oral Rehabil 2007 Aug;34(8): 622-630.

11. Andersson M, Odén A. A new all-ceramic crown - a densesintered, high purity alumina coping with porcelain. Acta Odontol Scand 1993 Feb;51(1):59-64.

12. Ozcan M, Alkumru HN, Gemalmaz D. The effect of surface treatment on the shear bond strength of luting cement to a glass-infiltrated alumina ceramic. Int J Prosthodont 2001 Jul-Aug;14(4):335-339.

13. Ozcan M, Vallittu PK. Effect of surface conditioning methods on the bond strength of luting cement to ceramics. Dental Mater 2003 Dec;19(8):725-731.

14. International Standards Organization. ISO standard. 11405:2003. Dental materials - testing of adhesion to tooth structure. Geneva: ISO/TS; 2003.

15. Madani M, Chu FC, McDonald AV, Smales RJ. Effects of surface treatments on shear bond strengths between a resin cement and an alumina core. J Prosthet Dent 2000 Jun;83(6):644-647. 
16. Awliya W, Odén A, Yaman P, Dennison JB, Razzoog ME. Shear bond strength of a resin cement to densely sintered high-purity alumina with various surface conditions. Acta Odontol Scand 1998 Feb;56(1):9-13.

17. Ozcan M, Nijhuis $H$, Valandro LF. Effect of various surface conditioning methods on the adhesion of dual-cure resin cement with MDP functional monomer to zirconia after thermal aging. Dent Mater J 2008 Jan;27(1):99-104.

18. Blatz MB, Sadan A, Kern M. Resin ceramic bonding: a review of the literature. J Prosthet Dent 2003 Mar;89(3):268-274.

19. Begazo CC, de Boer HD, Kleverlaan CJ, van Waas MA, Feilzer AJ. Shear bond strength of different types of luting cements to an aluminum oxide-reinforced glass ceramic core material. Dent Mater 2004 Dec;20(10):901-907.

20. Hummel M, Kern M. Durability of the resin bond strength to the alumina ceramic Procera. Dent Mater 2004 Jun;20(5):498-508.

21. Kato H, Matsumura H, Ide T, Atsuta M. Improved bonding of adhesive resin to sintered porcelain with the combination of acid etching and a two-liquid silane conditioner. J Oral Rehabil 2001 Jan;28(1):102-108.

22. Shimada Y, Yamaguchi S, Tagami J. Micro-shear bond strength of dual-cured resin cement to glass ceramics. Dent Mater 2002 Jul;18(5):380-388.

23. Blatz MB, Sadan A, Arch GH Jr, Lang BR. In vitro evaluation of long-term bonding of Procera AllCeram alumina restorations with a modified resin luting agent. J Prosthet Dent 2003 Apr;89(4):381-387.

24. El Zohairy AA, De Gee AJ, Hassan FM, Feilzer AJ. The effect of adhesives with various degrees of hydrophilicity on resin ceramic bonding durability. Dent Mater 2004 Oct;20(8):778-787.

25. Blatz MB, Sadan A, Soignet D, Blatz U, Mercante D, Chiche G. Long-term resin bond to densely sintered aluminum oxide ceramic. J Esthet Restor Dent 2003 Nov;15(6):362-368; discussion 369.

26. Nakamura S, Yoshida K, Kamada K, Atsuta M. Bonding between resin luting cement and glass infiltrated aluminareinforced ceramics with silane coupling agent. J Oral Rehabil 2004 Aug;31(8):785-789.

27. Yoshida K, Tsuo Y, Atsuta M. Bonding of dual-cured resin cement to zirconia ceramic using phosphate acid ester monomer and zirconate coupler. J Biomed Mater Res B Appl Biomater 2006 Apr;77(1):28-33.

28. Sen D, Poyrazoglu E, Tuncelli B, Göller G. Shear bond strength of resin luting cement to glass-infiltrated porous aluminum oxide cores. J Prosthet Dent 2000 Feb;83(2):210-215.

29. Chung $\mathrm{KH}$, Hwang YC. Bonding strengths of porcelain repair systems with various surface treatments. J Prosthet Dent 1997 Sep;78(3):267-274. 